DOI: $10.5272 /$ jimab.2012184.229

Journal of IMAB - Annual Proceeding (Scientific Papers) 2012, vol. 18, book 4

\title{
EARLY DETECTION OF OSTEOPOROSIS IN PATIENTS OVER 55 USING ORTHOPANTO- MOGRAPHY
}

\author{
Stefka Peycheva*, Hristina Lalabonova*, Hristo Daskalov** \\ *Department of Maxillo-facial surgery, ** Department of Oral surgery, \\ Faculty of Dental Medicine, Medical Univesity - Plovdiv, Bulgaria
}

\begin{abstract}
:
Osteoporosis is a condition characterized by a loss on bone mineral density and there is micro- architectural deterioration in bone tissue leading to fracture.

Dental radiographs are the most frequently used imaging modalities for teeth and jaw pathology.

The purposes of this study were to review the role of panoramic radiograph in routine dental treatment for an initial evaluation of osteoporosis and to discuss the reliability and accuracy of reported panoramic indices.

We present to the dental society the Klemetti index (Mandibular cortical index-MCI). In this technique the inferior cortex both sides of the mandible, distal to the foramen mentale, is classified into three groups, according to the mandibular bone thickness, shape and porosity.

C1- normal cortex- the endosteal margin of the cortex is even and sharp on both sides.

C2- mildly to moderately eroded cortex, the endosteal margin has resorptive cavities with cortical residues one to three layers thick on one or both sides.

C3- Severely eroded cortex, the cortical layer forms endosteal cortical residues and is clearly porous.

Patients having positive findings related to MCI should be evaluated further for potential risk of osteoporosis and could be referred to a medical specialist for densitometry.

In conclusion, valuation of mandibular cortical index (thickness and shape of inferior cortex of mandible), measured from panoramic radiography was a simple technique in osteoporosis screeming of dental patients, giving the maximum benefit of being radiographed.
\end{abstract}

Key words: Mandibula, Klemetti index (Mandibular cortical index- MCI), Panoramic radiography, Osteoporosis, Dental treatment.

\section{INTRODUCTION:}

Osteoporosis is a condition characterized by a low bone mineral density (BMD) and microarchitectural deterioration leading often to fractures. Diagnosing it as early as possible is of paramount importance in preventing complications from osteoporosis. $(1,2)$
The findings obtained by orthopantomography (OPG) presented as mandibular indices can be used as early evidence of any changes in the total bone mineral density. These indices can be determined by the number of lost teeth, the alveolar bone resorption, the lamina dura width, the mandibular cortical thickness, and by the morphology of the inferior cortical edge of the mandible. $(3,4,5)$

The $\mathrm{X}$ ray method that is most frequently used to detect any pathological changes in the teeth and the jaws for dentists is orthopantomography. It can be used as an efficacious technique for early osteoporosis screening thus defining new clinical targets in the dental practice.(6)

The aim of the present study is to acquaint dental community with the mandibular cortical index $(\boldsymbol{M C I})$ referred to as Klemetti index, an index that is obtained by OPG and utilised here to diagnose osteopenia and osteoporosis.

\section{METHOD:}

There are many OPG-based indices and techniques using which we can determine and analyse the mandibular bone by using various parameters of the bone. (Fig. 1).

\section{Figure 1.}

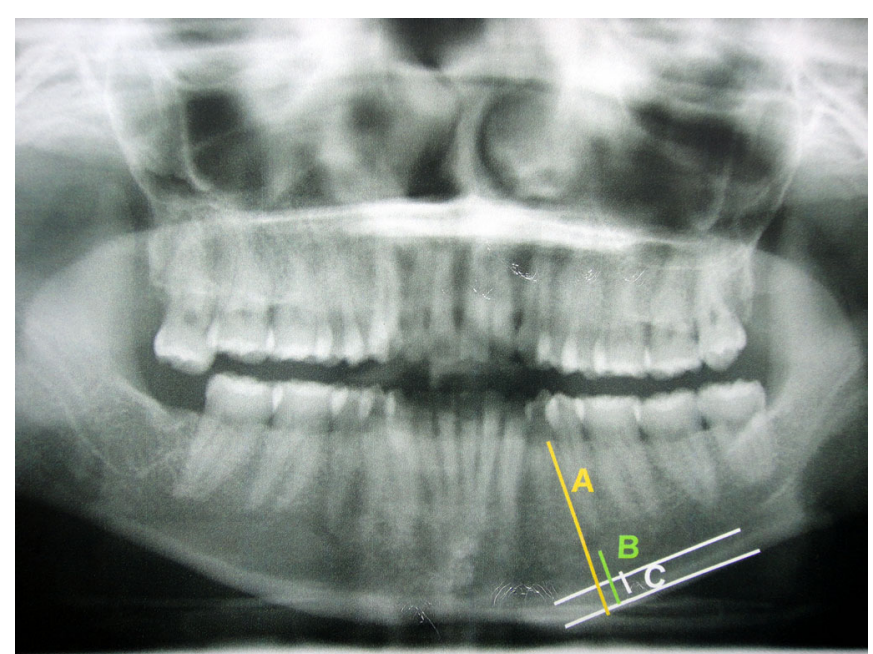


A. Total bone height (width); B. Mandible height measured from mental foramen to the inferior cortical edge of the mandible; $C$. Thickness of the inferior cortical edge of the mandible (mandibular cortex).

Determination of the bone quality based on the analysis of OPG is most often performed using the Klemetti index $(M C I)$. It is used to seek evidence of resorption and osteoporosis in the inferior cortical edge. It is basically about the following: The appearance of the inferior cortical edge of the mandible (the $\mathrm{C}$ parameter in Fig. 1) in the region distal to the mental foramen can be classified in three categories depending in the degree of resorption:

Figure 2.

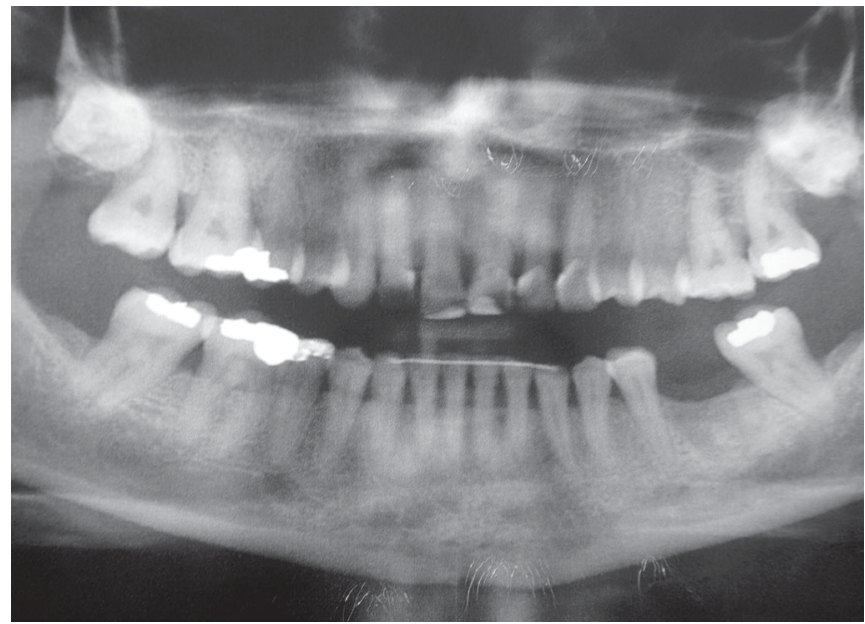

Figure 3.

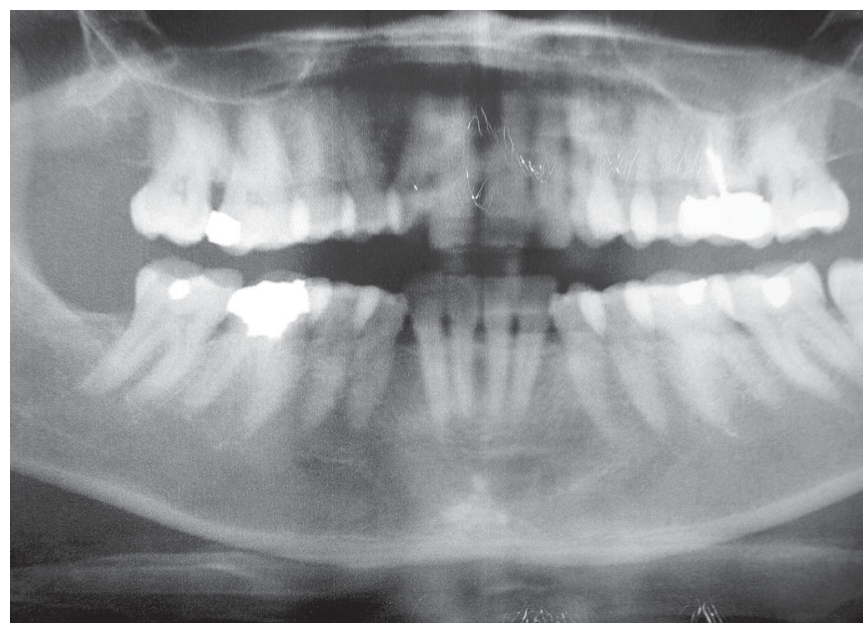

Figure 4.

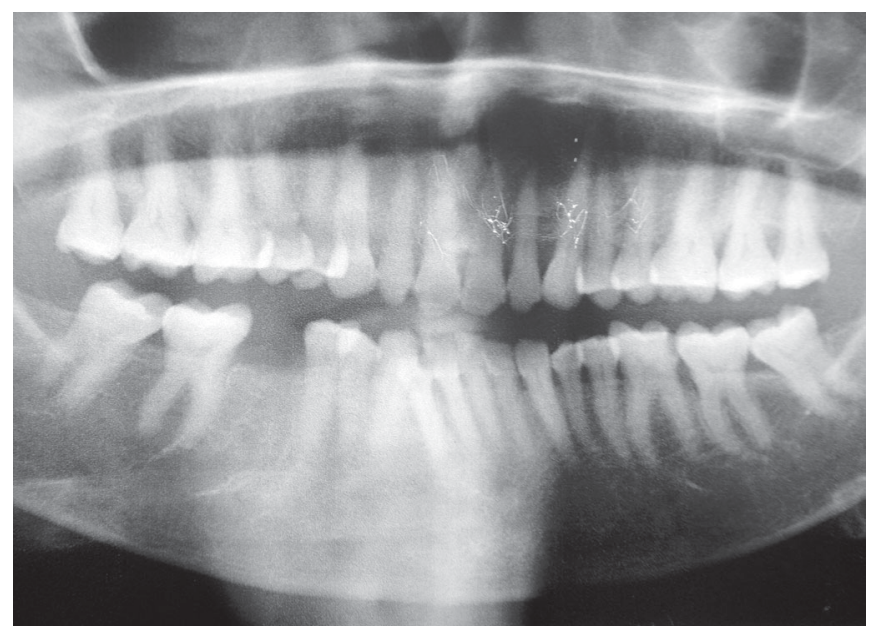

$\mathrm{C}_{1}$ - normal cortex. The endostic margin is uniform and marked on both sides. (Fig. 2)

$\mathrm{C}_{2}$ - Slightly or moderately eroded cortex. The endostic margin appears to have resorption cavities and cortical residues consisting of 1 to 3 thin layers (Fig. 3).

$\mathrm{C}_{3}$ - Cortex is severely eroded. The cortical bone is clearly porous and there is a significant amount of residue. (Fig. 4)

To illustrate the application of the index we present the 71-year-old V.I.S. who received OPG study due to inflammation in the mandible. His mandibular cortical index was $\mathrm{C}_{2}$. The patient was referred to endocrinologist for consultation. We studied the general bone density of the patient using bone density assessment method and found that the patient had a mild form of osteoporosis - bone density $83 \%$, T score 1.73 (Fig. 5, 6).

\section{Figure 5.}

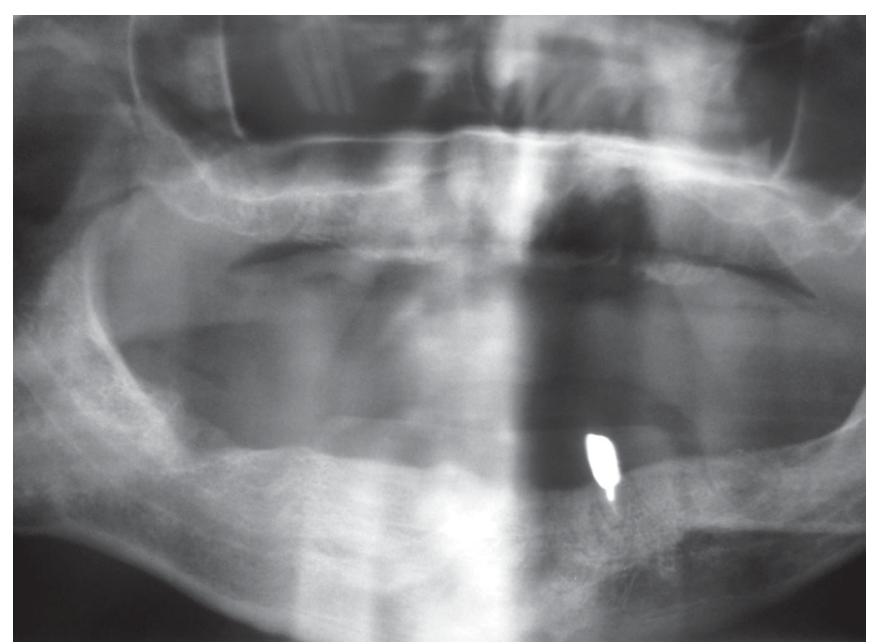


Figure 6.

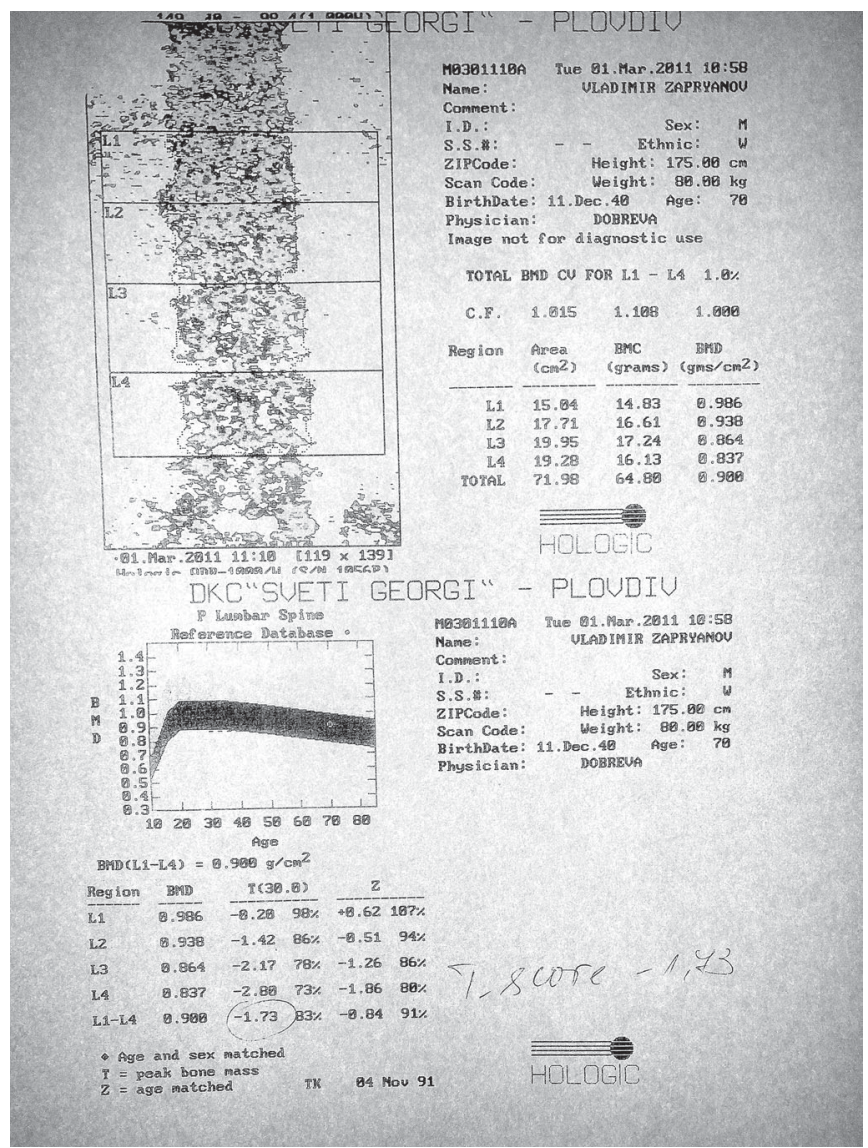

CONCLUSION:

The variations in the width and shape of the inferior cortical edge of the mandible are seen clearly on OPG. Determination of Klemetti index is an easy and simple screening method where dentists use an $\mathrm{X}$ ray made for other reasons without the patient being additionally burdened radio logically and financially.

\section{REFERENCES:}

1. Alexandra Lozano, Anna-Maria Borisova. Endocrinology. Sofia; Marin Drinov; 2000; 1100.

2. Horner K, Devlin H, Harvey L. Detecting patients with low skeletal bone mass. J Dent. 2002 May;30(4): 171-175. [PubMed]

3. Klemetti E, Kolmakow S. Morphology of the mandibular cortex on panoramic radiographs as an indicator of bone quality. Dentomaxillofac Radiol. 1997 Jan;26(1):2225. [PubMed]

4. Klemetti E, Kolmakow S. Kroger H. Pantomography in assessment of the osteoporosis risk group. Scand J Dent Res. 1994 Feb;102(1):68-72. [PubMed]

5. Nakamoto T, A Taguchi, M Ohtsuka, Suei Y, Fujita M, Tanimoto K, et al. Dental panoramic radiograph as a tool to detect postmenopausal women with low bone mineral density: untrained general dental practitioners' diagnostic performance. Osteoporos Int 2003 Aug;14(8):659-64. Epub 2003 Jun 24. [PubMed] [CrossRef]

6. Kositbowornchai S. Osteoporosis Detection on Panoramic. Journal of the Dental Association of Thailand 2009 Oct-Dec;59(4). 213-221.

\section{Corresponding author:}

Dr. Stefka Peycheva

Department of Maxillo-facial surgery, UMBAL "Sv. Georgi" - Plovdiv 66, Peshtersko shose str., 4000 Plovdiv, Bulgaria e-mail: paecheva_steffi@yahoo.com; 